\title{
O papel da intercalação na reescrita
}

\author{
Raquel Salek Fiad \\ Juliene da Silva Barros \\ Unicamp
}

This paper proposes an interpretation of the relation between bracketing and rewriting. Our hypothesis is that rewriting is a metaenunciative activity and bracketing marks intercalations, which are metaenunciative phenomena as well, consequently both are used to mark the return of the subject to the text.

Este trabalho é uma proposta de interpretação das relações entre os parênteses e a reescrita. Nossa hipótese é a de que estes sinais servem para marcar o retorno do sujeito sobre seu texto porque a rescrita é uma atividade metaenunciativa e os parênteses são marcadores de intercalações, fenômenos igualmente metaenunciativos. Essa análise contribuirá tanto para os estudos de reescrita, que se voltam para a compreensão do trabalho do sujeito em fase de aquisição da linguagem escrita, como para um melhor entendimento das intercalações, pois esses fenômenos, parecendo marginais a estudos não-enunciativos, foram relegadas a um estatuto secundário, não se verificando em sua análise o cuidado e o aprofundamento devidos.

\section{Contando uma história}

Era uma vez... um curso de produção escrita em língua materna em que, dentre outras coisas, discutiu-se a reescrita de textos. Uma aluna já vinha falando, há certo tempo, de fenômenos de interposição que, em muitos casos, são marcados por parênteses. Em alguns dos exemplos de reescrita, chamou a atenção justamente o uso dos parênteses. Desse encontro (não ocasional...) entre o parêntese e a reescrita, surgiu a idéia de um texto conjunto em que ousássemos compreender a relação entre os dois, indo além de uma posição ingênua que costumeiramente associa o parêntese ao que deve ser retirado de um texto quando é reescrito. Nossa hipótese é que esse olhar meramente descritivo não dá conta da 
questão, pois a relação entre os dois é de outra natureza: a reescrita é uma atividade metaenunciativa que constitui um retorno sobre o dizer, sendo, portanto, esperado que o parêntese seja usado para marcar essa interposição do sujeito. O desdobramento dessa história poderá ser acompanhado a seguir.

\section{Retomando a reescrita}

Apresentamos aqui um breve histórico de um certo conjunto de pesquisas sobre reescrita a fim de situar nosso interesse particular nesse fenômeno'.

Nos estudos de aquisição da modalidade escrita da linguagem que temos desenvolvido tem sido adotado um paradigma indiciário de investigação (cf. Ginzburg, 1939), permitindo-nos atribuir uma relevância especial aos dados idiossincráticos e singulares. Acreditamos que os dados de aquisição da escrita, principalmente os da escrita inicial, são importantes indícios do processo através do qual se vai continuamente constituindo e modificando a complexa relação entre o sujeito e a linguagem.

A partir da coleta de um conjunto significativo de textos escritos por crianças, adolescentes e adultos, produzidos em contextos diferenciados, formamos um banco de dados que têm sido continuamente analisados. Os dados nos mostraram a necessidade de considerarmos, como significativas, em uma teoria de aquisição da linguagem escrita, as manifestações de comportamentos episódicos e singulares dos sujeitos. Além disso, os dados têm mostrado situações de grande instabilidade, em que a linguagem é continua e rapidamente (re)elaborada: são situações em que o sujeito demonstra, por escrito, sua preocupação com determinado aspecto da linguagem.

Merecem particular atenção para a discussão da singularidade e para a discussão da relação sujeito/linguagem ao longo do processo de aquisição os dados em que estão presentes episódios de reescrita. Ao assumirmos, com base em Franchi (1987) que a linguagem pode ser

\footnotetext{
Fazemos referência às pesquisas realizadas no âmbito do Projeto Integrado de Pesquisa "A relevância teórica dos dados singulares na aquisição da escrita", desenvolvido no IEL/Unicamp.
} 
tomada como atividade, como trabalho, e é constantemente modificada pelo sujeito que sobre ela atua, consideramos que esses episódios mostram algum tipo de trabalho que o sujeito realiza com a linguagem.

É importante mencionar que nossos estudos se diferenciam de outras abordagens que esse fenômeno vem recebendo. Por um lado, existe uma tradição reconhecida de análise de manuscritos de escritores consagrados visando depreender a gênese dos textos literários. Por outro, existe uma preocupação com o aspecto didático, presente em propostas de ensino de escrita que incluem a atividade de reescrita na escola. As pesquisas voltadas para a análise de reescrita em textos de escolares - que são as de que mais nos aproximamos - vêm se realizando nos últimos quinze anos, movidas pelo interesse maior pelo processo da escrita do que pelo seu produto final. Dentre as várias referências teóricas que têm orientado essas pesquisas, Fabre-Cols (2002) menciona as teorias da enunciação (Benveniste, Culioli) e o dialogismo de Bakhtin. A partir das teorias da enunciação, a análise dos manuscritos mostra que é possível reconstruir parcialmente o processo de produção textual a partir das marcas enunciativas inscritas nos rascunhos e nas rasuras.

Os dados por nós analisados têm mostrado que a prática de reescrita pode ocorrer desde as primeiras escritas e são esses episódios, que podem ser detectados nos textos produzidos em diferentes situações escolares e não-escolares, que nos chamam a atenção como reveladores do trabalho que os escreventes realizam com a linguagem. Esses episódios correspondem à caracterização que Fabre e Cappeau (1996: 54) propõem para o termo reescrita: modificações escriturais pelas quais os diversos estados do texto constituem as sequiências retomadas, que resultam em um texto terminal.

Quando olhamos para os textos infantis e perguntamos se as crianças reescrevem e o que reescrevem, encontramos episódios de reescrita que nos surpreendem, por indicarem que, desde o início da atividade de escrita, há marcas enunciativas do processo da escrita. Antes mesmo de dominarem o sistema alfabético de escrita do português, as crianças rasuram letras, refazem-nas. As crianças apagam, inserem, substituem letras, palavras, expressões, frases, deixando marcas de sua trajetória individual. A análise dos dados nos remete, por um lado, às marcas individuais e, por outro, aos fenômenos gerais da enunciação escrita.

Em muitos episódios de reescrita, encontramos os parênteses como marca específica dessa intervenção do sujeito. Para compreender o 
funcionamento dos parênteses no âmbito das discussões sobre reescrita, faz-se necessário proceder antes a algumas considerações de base para situá-lo no interior de uma discussão maior na qual se insere e, a partir deste horizonte, destacar os aspectos a serem enfatizados nesta reflexão particular.

\section{Situando os parênteses}

Em nossa tese de doutoramento, estudamos certos fenômenos de interposição como as chamadas digressões, inserções e notas de rodapé. Essas três manifestações são abordadas como variantes de um processo mais amplo designado intercalação, a partir de uma interface entre fundamentos teórico-epistemológicos da Lingüística Textual (LT) e da Análise do Discurso (AD). Para tanto, partimos da hipótese de que esses fenômenos são ambíguos - pois se direcionam tanto à unidade quanto à dispersão -, o que os situa teoricamente entre a textualidade e a discursividade. Essa interface possibilita não apenas a abordagem conjunta dos três fenômenos citados, mas também sua caracterização como manifestações metaenunciativas (de acordo com a terminologia de Authier-Revuz, 1998), que se constituem como um retorno sobre o dizer, desdobrando a enunciação em pontos específicos, além de permitir redefini-los como resultados de uma interposição do sujeito no texto.

Essa interposição metaenunciativa por meio da qual o sujeito constitui intercalações revela aspectos vários quanto ao funcionamento enunciativo e aqui destacaremos dois deles para encaminhar a reflexão. O primeiro diz respeito aos modos de emergência das intercalações, onde se podem observar as formas de disposição no texto - conforme estejam no continuum textual ou em sua perigrafia -, e as formas de marcação conforme sejam limitadas por marcadores verbais (como bracketing devices e verbos dicendi) ou por marcadores não-verbais (como parênteses, travessões, vírgulas, números, asteriscos e outros "não oficiais"). O segundo diz respeito às formas metaenunciativas constituídas por meio das intercalações - as quais desempenham as funções particulares como justificativas, explicações, correções, reformulações retóricas, alusões e muitas outras. Para interpretar as variações quanto à emergência e ao funcionamento das intercalações, temos lançado mão dos conceitos de gênero e de estilo, pois acreditamos 
que, no limite, o trabalho do sujeito com as intercalações revela um trabalho de constituição de autoria, dentro das restrições peculiares a cada gênero e dentro das possibilidades de escolhas estilísticas. ${ }^{2}$

$\mathrm{Na}$ análise a seguir, dois aspectos interessam de modo específico: o uso dos parênteses como um marcador de intercalação e a função metaenunciativa de correção (com a possibilidade de alusões circunstanciais ao travessão, por um lado, e à função metaenunciativa de reformulação retórica, por outro, para estabelecer necessários elementos de comparação que especificam os dois aspectos em foco). A ênfase nestes dois aspectos, no entanto, não pode, de forma alguma, fazer com que se perca de vista que essas intercalações parentéticas com função de correção são interposições metaenunciativas, que indiciam o trabalho do sujeito com o texto. É isso, aliás, que relaciona os parênteses à reescrita; é isso que faz com que, na atividade de reescrita, os parênteses possam ser uma das formas de marcar o retorno do sujeito sobre o texto.

\section{Repensando a relação dos parênteses com a reescrita}

Há uma visão segundo a qual as intercalações marcadas por parênteses constituem-se de comentários acessórios, irrelevantes e até mesmo desnecessários. Essa é, de forma geral, a visão aceita no ensino, a qual vê-se legitimada pela gramática tradicional e por "estudos" nela inspirados, como os manuais de redação e outros, em que sobrevive implícita ou explicitamente - um discurso que depõe contra as intercalações em geral, associando-as à idéia de descontinuidade sintática e fragmentação textual. Por conta desse olhar superficial e equivocado, o fato de o aluno usar parênteses para intercalar suas rasuras no texto é muitas vezes interpretado como um mero isolamento do que não serve ao texto, como uma forma de separar o que será retirado na reescrita. Não negamos que a intercalação limitada por parênteses possa desempenhar no texto esta função específica de correção, mas ela não é a única, para começar. Além disso, é deixada de lado uma questão fundamental que é anterior a esse olhar meramente descritivo - trata-se

\footnotetext{
'Para um tratamento mais detalhado dessas questões sugerimos a leitura de "Intercalação, metadiscurso e autoria: por uma análise textual-discursiva da interposição na escrita" (Barros, 2000).
} 
da necessidade de se compreender porque, nesses casos, o aluno usa justamente os parênteses. O funcionamento desse marcador permite-nos interpretar que ele isola a rasura não simplesmente porque nele caberia o que é desnecessário; ele isola a rasura porque a reescrita é um retorno metaenunciativo - é uma meta-escrita - sendo, portanto, de absoluta coerência que os parênteses, um marcador de intercalação, sirva para marcar essa interposição do sujeito em sua escrita.

E esse trabalho do sujeito tanto reafirma as funções da rasura já apontadas em trabalhos anteriores (cf. Abaurre, Fiad e MayrinkSabinson,1997) no sentido de que os alunos rasuram para substituir ou anular desde grafemas e palavras até fragmentos textuais maiores, como expressões, frases ou parágrafos inteiros, quanto mostra uma variação no modo como usam os parênteses, como poderá ser visto nos dados a seguir. Mas antes de proceder a este e aos demais passos da análise, é importante tentar sugerir uma diferença entre dois tipos de fenômenos. Essas interposições com função corretiva têm, à primeira vista, um funcionamento semelhante ao da simples rasura. O dado abaixo mostra que, num mesmo parágrafo, o sujeito tanto marca os itens a serem corrigidos com o isolamento entre parênteses como o fazem por meio de rasuras simplesmente.

Em uma certa nate, en estan saindo do cimirra. Tenta acoberdo de assisture co filme $2(0)$ predador.' Eram (oze) onge da moits Eruzei a rua. Dle repente. Tadas as lezes se apagam. Comecci a ouvir ruidos estran has, também passos, cams se alguém mi segusse. Quando olthei para trá)... nimguém. Etare. ventando foerte. Ces ruas desertas. Estana só en no mio da nuela escurida. Takug nōo

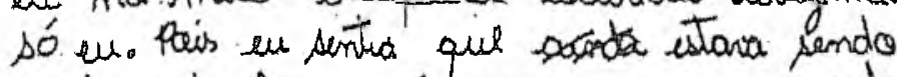
persegudo. ler será que rka apmas minha imaginarāo?

As duas marcas presentes nesse fragmento - a parentetização de oze e a rasura de ainda, na terceira e na décima linhas, respectivamente - podem levar a pensar que o fenômeno é o mesmo, até porque se trata de uma indicação de que ambos os itens são excluídos da leitura e 
certamente não constariam num possível "texto terminal" (para retomarmos a expressão anterior de Fabre). Uma outra razão que pode levar a pensar que se trata de algo indistinto é o tratamento indiscriminado que os dois tipos de rasura recebem na escola. Quantas vezes os professores não nos sugeriram colocar o "erro" entre parênteses ou riscálo, apenas? Quantas vezes nós mesmos, como o sujeito do texto anterior, marcamos a rasura das duas formas, sem nos inquietarmos com essa indiferenciação do diferente? Aprendemos a pensar que se trata da mesma coisa e, num sentido geral de rescrita como metaenunciação, são mesmo formas de retornar sobre o escrito.

Contudo, talvez possamos argumentar que, embora servindo a um mesmo processo geral e embora feitos por um mesmo sujeito, em um mesmo parágrafo e até mesmo com uma função específica claramente similar (a correção), não podem ser tomados como a mesma coisa (até porque riscos são riscos e parênteses são parênteses). No caso dos parênteses, haveria a particularidade de ser uma dupla marcação. Não só há uma volta sobre ao texto, mas também há uma marcação dobrada.

Veja o leitor como no caso abaixo o aluno usa sistematicamente a rasura em forma de risco para anular o que não serve a seu texto.

\section{(Q) laberatónis maluco.}

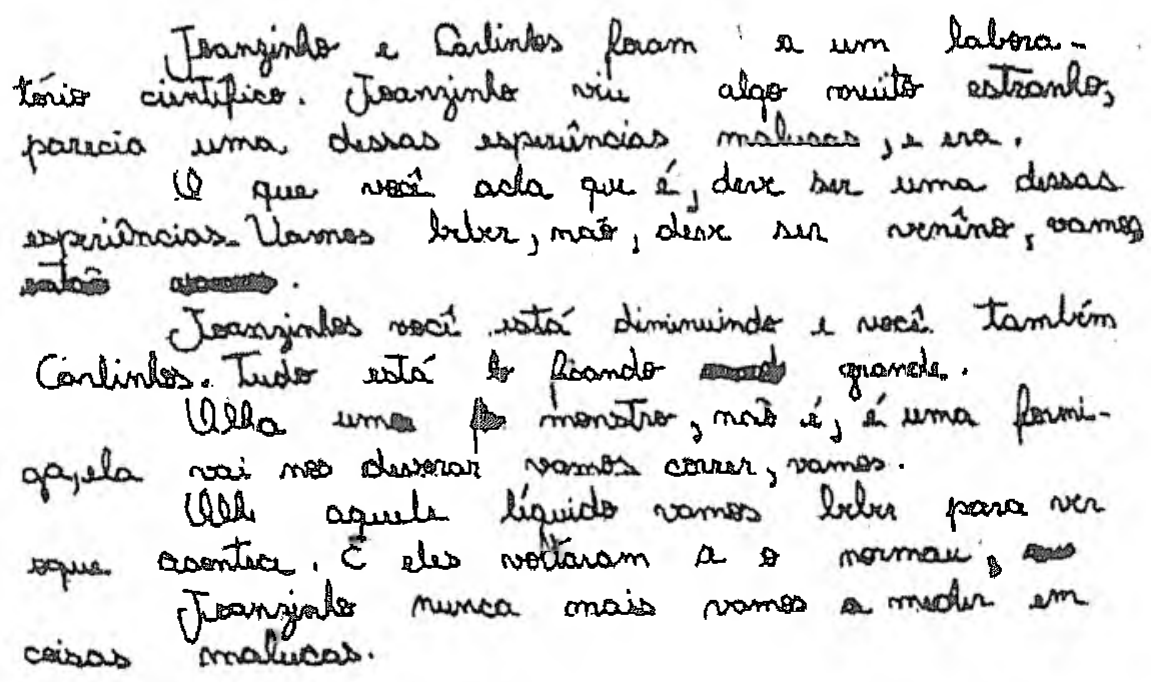


Não faremos maiores considerações sobre este dado neste ponto, pois ele será retomado adiante. Deter-nos-emos a partir de agora nas rasuras que envolvem o uso dos parênteses, tematizando a exploração diferenciada desse sinal. O primeiro caso é uma rasura interposta por parênteses: há uma dupla marcação, um cuidado dobrado para avisar ao leitor a anulação de fragmentos dentro do texto.

\section{Um dia de lmverno}

Sicabou o Batromo, nas prodíamsos ir

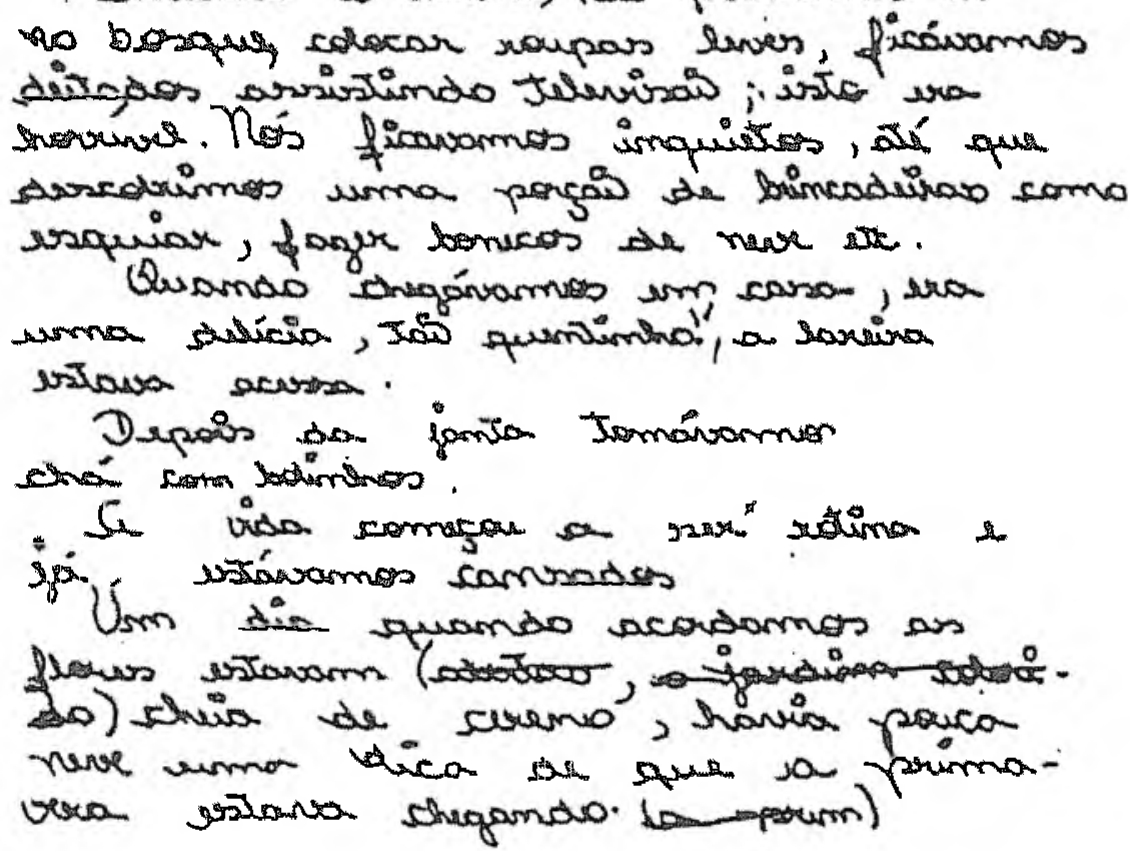

As duas rasuras efetuadas no último parágrafo parecem servir a dois interesses diferentes. Na primeira, o sujeito faz uma reformulação no período, para anunciar a primavera que chegara após um inverno, que, conforme o texto, já se tornava cansativo. O sujeito anula o trecho (aberas, o jardimeolorido), pois parece um salto muito brusco de uma estação à outra, sustentando um pouco essa conclusão com idéias de transição, que, além de refletirem esse processo de mudança, por mostrar suas dicas, como bem diz o locutor, deixam sem dúvida o período mais 
lógico do ponto de vista narrativo e mais elegante: Um dia quando acordamos as flores estavam cheia de sereno, havia pouca neve uma dica (será que o sujeito sabe do paradigma indiciário?) de que a primavera estava chegando. A segunda rasura entre parênteses simplesmente anula o início de um novo período sobre a primavera (a prim), talvez numa desistência mesmo de continuar esse assunto específico, já que o título do texto orienta que se fale de "Um dia de inverno", mantendo-se possivelmente dentro do que reza um princípio de relevância. Essas duas correções são cuidadosamente destacadas por parênteses.

As correções entre parênteses também indicam erros ortográficos, substituições lexicais, ajustes sintáticos e outros, como poderá ser visto nos dados a seguir. No próximo texto há uma mistura dos dois marcadores. Se no anterior havia uma coincidência dos dois gestos do sujeito num mesmo ponto, aqui, usa-se ora o simples rabisco, ora o rabisco entre parênteses.

\section{Um dia de Śnverno}

Nurma mambla de domingo, a vento saprou qulodo. Af loreina ertowa persa.

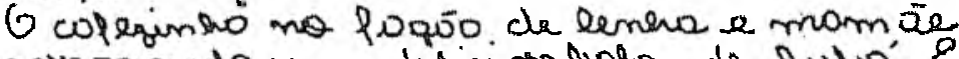
prepowndo um delicioboloto de pulá. E Mata sentoda na rofá com 12 colerta no

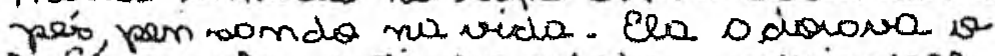
f risa, oquele ventimbo gelvelo e principue. mente o bolo que mimsie potic no in veuno.

Pows ela a pria ena a mesma casa quse um dia de sal. Os possawos corrtaran Qrovi j.. E noo esquecia do nom ovodo que ponicla que a cho mava honge tamberm tia sombizua em se wask is ser muito Qtipis.

Friara tumberm oduanona andarasi, peis, se sentia mellow, principulm enjte

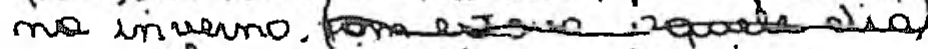
rais, the shison' squele div As! Coma sevia from se todas do venes o vinuerno chequasse numb m ónbé de dorningo. 
Nesse texto as duas rasuras mostram questões bem diferentes. Na primeira ( $2^{\circ}$ parágrafo), o sujeito simplesmente rabisca um equívoco ortográfico qois, abandonando essa tentativa para substitui-la em seguida por sua grafia correta coisa. A segunda rasura utiliza-se dos parênteses para isolar um trecho que o sujeito suprimirá (eomo aquele dia). Aqui, como no segundo caso analisado no texto anterior, há uma reestruturação maior no interior do parágrafo. O sujeito substitui a oração comparativa (se a NGB permitisse, diríamos uma modal) por uma explicativa pois ele chegará aquele dia. Há uma mudança na estrutura sintática, o que muda o modo de dizer e o efeito do dito: o anúncio de que o inverno chegara naquela manhã de domingo tem mais força nesta estrutura sintática do que na anterior. Não dizemos que o aluno pensa em todas essas coisas ao escrever seus textos, mas, mesmo que não possua a metalinguagem, possivelmente percebe os efeitos da transformação efetuada. No caso, há uma força performativa muito maior no anúncio da segunda versão do que na alusão da primeira. Como pode ser visto, essas interposições com função corretiva servem a propósitos variados, tão variados como são elas próprias.

O caso a seguir mostra mais uma variação no uso dos parênteses. Desta vez, trata-se, como foi antecipado no primeiro caso, de uso apenas dos parênteses, como forma de substituir equívocos que o sujeito vai detectando em pontos localizados do texto. No texto que trata das aventuras dO cavalo Chico, os parênteses são usados sistematicamente como marcadores de correções, sem haver a menor preocupação de rasurar o que neles se insere, já que em todo os casos usa-se simplesmente esse recurso e a seguir vem o item que substitui o intercalado.

Esse texto mostra alguns casos de substituição feita após os parênteses, as quais variam em termos dos aspectos a serem corrigidos. Nos três primeiros casos, as rasuras anulam equívocos ortográficos: $(O$ cavavo) O cavalo, (cavaidas) cavalhadas, (quebo) quebrou; no quarto, há a substituição de um item já refeito, mas que, talvez porque permaneça com problemas de legibilidade, é abandonado (em) em; e, no quinto, há uma reformulação (na que) Aquele. Todos esses casos - é interessante notar - são correções efetivas, mas dispensam qualquer rabisco. Todos esses parênteses foram "deletados" do texto numa segunda versão a que tivemos acesso, mas, mesmo que não houvesse outra versão - está claro - o que se inseriu entre parênteses é nulo (a substituição seguida mostra 
exatamente isso). O questionamento desse fato é de alta revelância, pois nos casos anteriores mostramos a anulação de trechos do texto ou pelo simples rabisco, ou pelo rabisco interposto em parênteses, mas aqui apenas os parênteses são usados. Aqui o interposto equivale ao nulo. Não há a menor preocupação em se rasurar para avisar ao leitor.

\section{Tematizando especificidades dos parênteses}

Tendo mostrado as variações no uso de parênteses relacionados à rasura, poderíamos nos interrogar, a título de hipótese, se essa variação teria a ver com escolhas que caracterizam possíveis seleções estilísticas, mas deixaremos esse assunto para o próximo tópico, pois aqui aproveitaremos a questão levantada para tentar propor duas especificidades em relação ao uso dos parênteses.

Eis a primeira. Poder-se-ia explicar o fato de o sujeito não rasurar o que se encontra no interior dos parênteses alegando que a substituição logo em seguida deixa claro seu propósito. Essa pode ser uma explicação, ou uma parte da explicação. Mas é importante não perder de vista que essa confiança de que o uso de parênteses anula algo pode ser um indício da sobrevivência na escola de um discurso que associa as intercalações em geral ao supérfluo, ao desnecessário, ao irrelevante. Nos casos anteriores marcava-se a supressão, por assim dizer, pelo risco, mas aqui nem isso é necessário. Parece tratar-se - ratificamos - de um indício da crença de que o isolamento de algo entre parênteses equivale ao risco, ao nulo, ao que não significa, ao que não vai ser lido. Sobrevive no imaginário escolar a idéia de que o intercalado entre parênteses nada significa, daí, em alguns casos, não se mostrar a preocupação em rasurá-lo.

Como mostramos na parte introdutória, a função de correção é unna dentre as muitas que as intercalações marcadas por parênteses preenchem, mas não se pode por conta disso tratar o conteúdo de toda e qualquer interposição parentética como dispensável. Esse julgamento das intercalações não apenas não é verdadeiro como também pode significar uma perda muito grande para o desenvolvimento da capacidade de leitura e de escrita. Pois ler o que está entre parênteses significa, no mais das vezes, ler a posição do autor do texto, seus comentários, julgamentos, questões que, no geral, são decisivas para a constituição da coerência do texto em termos textuais-discursivos. Efetuar intercalações significa não 
apenas aprender a se colocar nesse espaço enunciativo, como também aprender a mobilizar conhecimentos sintáticos e de ordenação textual, pois toda interposição é uma sobreposição enunciativa que interfere na sintaxe e na progressão textual.

Essa questão fica muito clara no texto a seguir, onde o uso de parênteses serve a funções bem diferentes e tão importantes quanto a de correção.

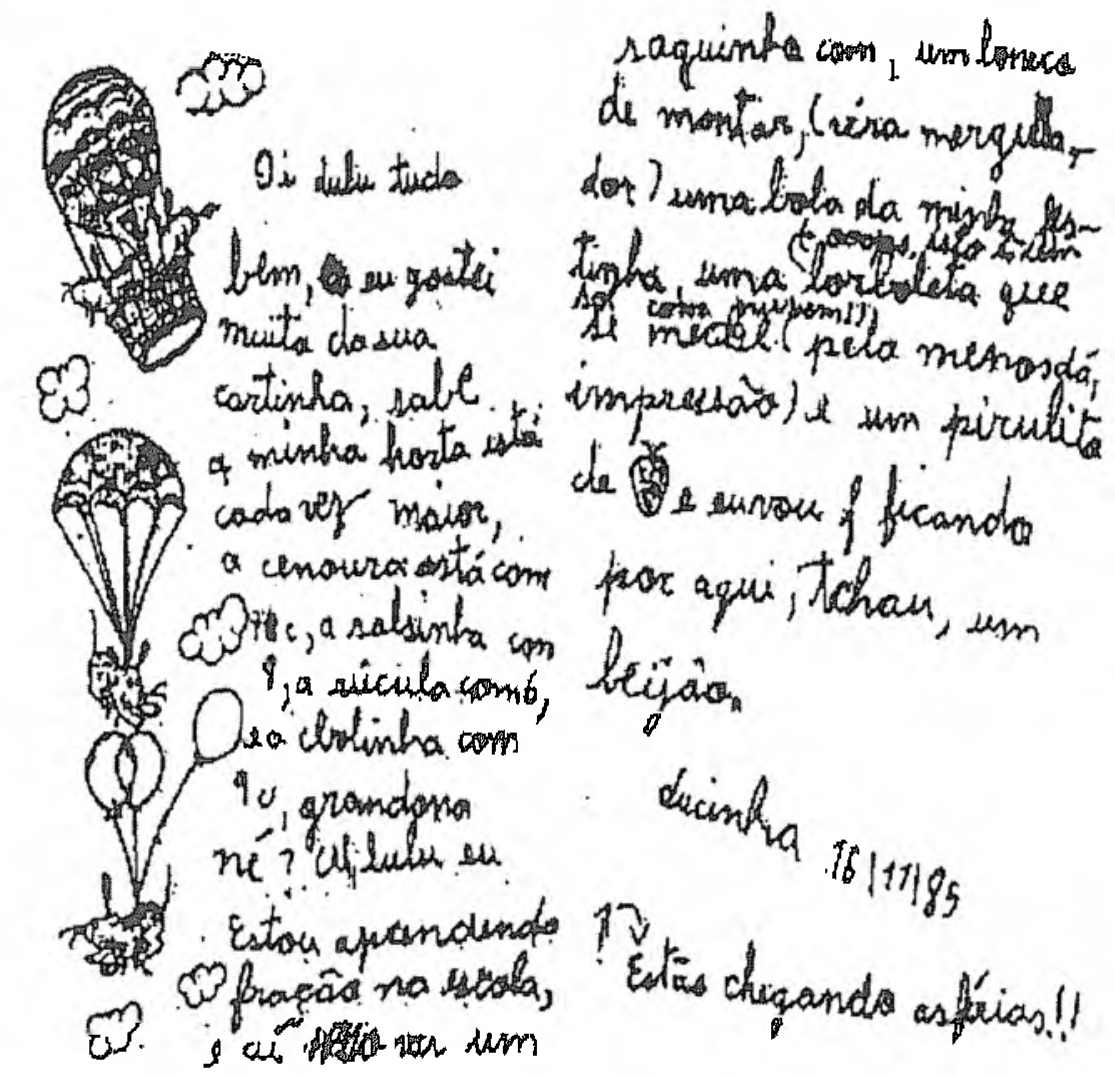

Neste texto, há três intercalações marcadas por parênteses, com funções bem específicas e todas elas diferentes da correção que ocorre nos anteriores. Neste texto, as correções são marcadas com rasuras por riscos, tendo o uso dos parênteses outras funções. A primeira apresenta uma explicação sobre o boneco de montar de que o sujeito fala (vira mergulhador); a terceira faz uma ressalva (pelo menos dá impressão); mas a segunda é a que mais importância tem para nossos propósitos: trata-se de uma reformulação retórica (ooops, isto é, um sol com nuvem). Conquanto todos os parênteses analisados nos textos anteriores não 
viessem a constar numa segunda versão (e nós pudemos conferir isso em alguns casos), aqui nenhum desses parênteses marca o que deve ser excluído (o que não impediria que, numa possível reescrita, o sujeito deliberasse fazê-lo), nem mesmo na suposta correção. Nesse caso específico, poder-se-ia ter a ilusão de que o marcador de paráfrase "isto é" (cuja adequação merece destaque, já que se trata da escrita de um sujeito na $3^{\mathrm{a}}$ série), marca uma possível substituição a ser feita na reescrita. Mas não é assim: esse é o funcionamento discursivo da paráfrase, ela mantém-se como leitura segunda, ao mesmo tempo paralela e sobreposta, mas não exclui a primeira.

Assim, nem mesmo frente a uma função com a qual guarda aparentes semelhanças, a correção pode ser equiparada. Ela é uma - e importante - função das interposições marcadas por parênteses, mas não se pode estender seu funcionamento às demais. Ser apagada é sua razão de existir, anular-se é seu modo de funcionamento, mas isso não quer dizer que se tenha que fazer vista grossa para todas as outras.

Mostrada essa primeira especificidade das intercalações parentéticas, gostaríamos de abordar rapidamente uma segunda especificidade, no intuito de destacar o uso dos parênteses em relação a outros marcadores. Por que, nos casos de correção, são usados justamente esses marcadores? Nas ressalvas, reformulações, explicações, usam-se o travessão, as vírgulas, mas não ocorre o mesmo com as correções. Nenhum dos textos anteriores traz uma correção isolada por marcadores que não sejam os parênteses (o mesmo professor de português que sugere colocar o erro entre parênteses, jamais o faria em relação ao travessão...). Isso parece tão óbvio do ponto de vista descritivo que a alguém poderia parecer desnecessário colocar questões a esse respeito. Mas talvez o óbvio possa dizer algo interessante sobre o uso desses marcadores, permitindo especificá-los em relação aos demais, pois, desde as gramáticas, diz-se que eles servem a propósitos diferentes e que a substituição não é gratuita. Não temos certezas, mas proporemos duas hipóteses: (i) os parênteses são, dentre esses sinais, os que mais se desprendem e que mais desprendem da sintaxe, sendo previsível que conteúdos deslocados, como as rasuras que sairão do texto, sejam interpostas entre parênteses; (ii) os parênteses são os únicos cujo uso só se dá aos pares, sendo o isolamento completo garantido com mais eficácia do que com o travessão, que pode ser combinado com o ponto e vírgula 
e com os sinais que encerram período, deixando muitas vezes a fronteira da intercalação um pouco imprecisa.

\section{Abrindo perspectivas}

Concluiremos com uma hipótese explicativa relacionando as questões discutidas anteriormente e, a seguir, abriremos uma perspectiva que a análise aponta. Os parênteses relacionam-se com a reescrita, servindo como um dos marcadores do retorno do sujeito sobre seu texto, porque a reescrita é uma atividade metaenunciativa - uma meta-escrita - por um lado, e porque os parênteses são marcadores de intercalações, as quais são também formas metaenunciativas, por outro. Enquanto marcador do gesto metaenunciativo do sujeito, os parênteses podem ser usados sozinhos ou em combinações diferentes com outros marcadores, como o rabisco; nesses casos, desempenham a função específica de correção, e nisto se diferenciam dos travessões e da vírgula, por exemplo, já que estes são sinais reservados a funçōes diferentes da rasura.

Uma questão sobre a qual não nos debruçamos e que deixaremos em aberto para outros trabalhos é a compreensão das variações que ocorrem nas formas de marcar as rasuras. Mostramos um uso diferenciado dessas "marcas", pois há casos de simples riscos, há outros de apenas parênteses e, ainda, combinações diferentes desses dois tipos de marcadores, como parênteses com riscos simultaneamente, parênteses e riscos alternados, parênteses com rasura e apenas a rasura. Como nossas pesquisas, por prismas diferentes, tematizam a questão do estilo já nos textos infantis, questionaríamos se esta variação pode ter a ver com escolhas e seleções que apontariam para a emergência de possíveis tendências estilísticas. Isso, no entanto, requer a consideração de um número maior de elementos, razão pela qual ficará como perspectiva para trabalhos seguintes.

\section{Referências bibliográficas}

ABAURRE, M. B. M.; FIAD, R. S.; MAYRINK-SABINSON, M. L. T. Cenas de aquisição da escrita. O sujeito e o trabalho com o texto. São Paulo: Mercado das Letras, 1997. p. 53-71.

AUTHIER-REVUZ, J. Palavras Incertas. As não-coincidências do dizer. 
São Paulo: Editora da Unicamp, 2001. Trad. Brasileira. 200p.

BARROS, J. Intercalação, metaenunciação e autoria: por uma análise textual-discursiva da interposição na escrita. In: PAULA, A. S.; COSTA, J. F. (Orgs.). Revista Leitura. Maceió: Edufal, n. 25, jan./jun. 2000. p. 141-152.

FABRE-COLS C.; CAPPEAU, P. Pour une dynamique de l'apprentissage: lécture/ écriture/réécriture. In: Études de Linguistique Appliquée, 101. Paris: Didier Erudition, 1996. p. 46-59.

FABRE-COLS, C. Réecrire à l'école et au collège. Issy-les-Moulineaux: ESF, 2002. 237p.

FRANCHI, C. Criatividade e gramática. In: Trabalhos em Lingüística Aplicada, Campinas, 9, p.5-45, 1987.

GINZBURG, C. Mitti Emblemi Spie: Morfologia e Storia. Torino: Einaudi, 1939, Mitos emblemas sinais: morfologia e história, Tradução de F. Carotti, São Paulo: Companhia das Letras, 1989. 